\section{Painful symptoms in depression: under-recognised} and under-treated?

\author{
ROBERT PEVELER, CORNELIUS KATONA, SIMON WESSELY \\ and CHRISTOPHER DOWRICK
}

\begin{abstract}
Summary Current diagnostic systems maintain an artificial division between 'physical' and 'psychological' disorders. This is exemplified by the way in which pain symptoms are dealt with in the context of depressive illness. The consequences of this are discussed, and ways to enhance the clinical care of patients with depression and pain are suggested.
\end{abstract}

\section{Declaration of interest All of the} authors were involved in the development of a review on depression and pain which was funded by Eli Lilly and Boehringer Ingelheim. However, the supporting companies were not represented at meetings and played no part in selecting the participants or preparing the report or this editorial. R.P. and C.K. have received speaker fees, hospitality or consultancy fees from Eli Lilly, Wyeth, Lundbeck, Novo Nordisk and Bristol Myers Squibb. S.W. has received support for conference attendance from Eli Lilly.

Psychiatric training is based on the tacit assumption that the clinical focus of psychiatry is on 'mental' disorder. To that end, diagnostic practice has been guided by the development of ICD-10 (World Health Organization, 1992) and DSM-IV (American Psychiatric Association, 1994). It is therefore not surprising that many psychiatrists are only dimly aware of the deep Cartesian dualism inherent in this approach, and of its potential adverse consequences for patients. In reality, the subjective experience of illness is not easily carved into separate 'mental' and 'physical' domains, and diagnostic practice that is based upon such dualism cannot do justice to the complexity of the individual experience of what is conventionally regarded as mental illness.
A clear example is seen in the classification of depressive disorders. There is an intimate relationship between experiences that are conventionally regarded as 'psychological' symptoms of depressive illness, and other subjective experiences, such as pain or fatigue, which are regarded as possible symptoms of physical illness. Some would even attempt to divide pain and fatigue symptoms themselves into mental and physical subtypes.

ICD and DSM do partly acknowledge the problem. In the chapter on mood disorders in ICD-10 it is stated that:

The relationship between aetiology, symptoms, underlying biochemical processes, response to treatment and outcome of mood disorders is not yet sufficiently well understood to allow their classification in a way that is likely to meet with universal approval.

However, it is then stated that 'the fundamental disturbance is a change in mood or affect' and that 'most other symptoms are either secondary to or easily understood in the context of such changes'. What is not stated is that this is a matter of convention rather than of fact. Similarly, DSM-IV acknowledges that physical symptoms are reported by patients, but again such symptoms are excluded from the list of diagnostic features. This is surprising, as the evidence for the association of depression and pain symptoms is overwhelming. This evidence comes mainly from epidemiological studies, but recent developments in neuroscience are also beginning to highlight common mechanisms underlying pain and depression (Von Knorring \& Ekselius, 1994).

A recent review of published literature on pain and depression (Katona et al, 2005) highlights these shortcomings and draws the following conclusions.

(a) Interpretation of research on pain and depression is hampered by a lack of clear terminology.

(b) Between two-fifths and two-thirds of patients with depression have painful symptoms. This is four times higher than the incidence of such symptoms in individuals without depression. Pain was reported by $54 \%$ of psychiatric in-patients in a Swedish study (Von Knorring et al, 1984).

(c) Depression and pain may share common pathogenic pathways, possibly involving serotonin (Blier \& Abbott, 2001). They are associated with the same range of predisposing environmental factors and early childhood experiences, and may be perpetuated by similar cognitive processes (Gilmer \& McKinney, 2003).

(d) The presence of pain may be associated with a poor response to treatment for depression, and with greater costs of care (Greenberg et al, 2003).

(e) The presence of residual symptoms, including pain, is a strong predictor of early relapse in patients with major depression.

(f) Doctors may contribute to increased use of resources by pursuing unnecessary investigations into the cause of depression-related pain.

(g) Tricyclic antidepressants such as amitriptyline are effective, and probably more so than selective serotonin reuptake inhibitors (SSRIs), in the treatment of pain. Serotonin and noradrenaline reuptake inhibitors (SNRIs) such as venlafaxine and duloxetine may also be more effective than SSRIs in reducing pain symptoms in patients with depression (Bair et al, 2004).

\section{TERMINOLOGY AND CLASSIFICATION}

Pain in patients with depressive disorders is frequently regarded as 'medically unexplained'. A joint report from the Royal College of Physicians \& Royal College of Psychiatrists (2003) notes that the management of patients with such symptoms is often inadequate. The report also states that it is unhelpful to think of these symptoms in either purely physical or purely psychiatric terms, and points out that the phrase 'medically unexplained' may be unhelpful and resented by patients. The traditional classification of diagnoses as either organic or psychological, and the use of terms such as 'functional', 'unexplained' and 'psychosomatic' to describe painful symptoms, are also unhelpful. For most pain sufferers, such terms generate 
frustration and distress and offer few pointers towards treatment, evidence-based or otherwise (Feinmann \& Newton-John, 2004).

\section{CLINICAL ASSESSMENT}

As many patients with depression suffer from pain of some kind, and in the light of the extensive evidence that such painful symptoms have an adverse effect on clinical outcome, psychiatrists should enquire about and pay attention to pain symptoms in patients who are diagnosed with depression. It is important to remember that chronic pain is an important independent risk factor for self-harm and suicide (Fishbain, 1999). We should also take into account any change in pain symptoms (and their impact) when assessing patients' progress.

\section{PRINCIPLES OF MANAGEMENT}

Patients with complex problems often struggle to convey the reality of their symptoms. Psychiatrists may consider that they lack the specialist knowledge and skills necessary to treat patients with depression and pain. Taking patients' pain seriously may therefore be therapeutic in its own right. The unstated assumption that physical symptoms are secondary to depression may hamper efforts both to engage the patient and to make reciprocal links between physical and psychological factors (as opposed to the unidirectional links that psychiatrists may prefer).

Techniques that have proved effective in the 'neutral' space of primary care can be grouped under the following four headings:

(a) helping the patient to feel understood (listening, taking physical complaints seriously, picking up cues of emotional distress, and exploring the patient's concerns about their illness)

(b) broadening the agenda (opening up the consultation to a discussion of both physical and psychosocial issues)

(c) making links (providing explanatory models of the ways in which physical and psychosocial problems may be linked)

ROBERT PEVELER, DPhil, FRCPsych, Mental Health Group, University of Southampton, Southampton; CORNELIUS KATONA, MD, FRCPsych, Kent Institute of Medicine and Health Sciences, University of Kent, Canterbury; SIMON WESSELY, MD, FRCPsych, Department of Psychological Medicine, King's College Hospital, London; CHRISTOPHER DOWRICK, MD, FRCGP, Department of Primary Medical Care, University of Liverpool, Liverpool, UK

Correspondence: Professor Robert Peveler, Mental Health Group, University of Southampton, Royal South Hants Hospital, Southampton SOI4 OYG, UK. Tel: +44 (0) 2380 825533; fax: +44 (0) 2380 234243; e-mail: R.C.Peveler@soton.ac.uk

(First received 5 May 2005, final revision 24 August 2005, accepted 30 September 2005)

(d) negotiating treatment (exploring concerns about treatment, including any side-effects that might be experienced).

Patients who are referred to specialist pain clinics are likely to receive multimodal, multidisciplinary interventions of demonstrated efficacy. Patients with depressive disorders who are referred for psychiatric treatment are, in contrast, much less likely to be managed by an integrated biopsychosocial approach. Indeed their pain symptoms may even be ignored, on the basis that they will disappear if only the 'underlying' depression can be treated effectively. Although it remains difficult so long as psychiatric services are deeply separated from mainstream medical and surgical services, more joint work in this area is clearly needed.

\section{CONCLUSIONS}

Pain in patients with depressive disorders has received inadequate attention in terms of both research and treatment. This topic represents an important gap in psychiatric training. Many psychiatrists feel poorly equipped to manage patients with complex presentations such as depression and pain, and may look to colleagues in the specialty of liaison psychiatry for assistance. Although such specialists may have a role in education and training, depression with pain occurs too frequently for it to be exclusively their domain. Twenty-firstcentury psychiatrists must move away from the dualism that currently besets Western medical practice if their patients are to receive optimal care.

\section{ACKNOWLEDGEMENTS}

We thank Charlotte Feinmann, Linda Gask, Huw Lloyd, Amanda C. de C. Williams and Liz Wager for their contributions to the review on depression and pain and the subsequent discussions which provided the stimulus for this editorial.

\section{REFERENCES}

American Psychiatric Association (1994) Diagnostic and Statistical Manual of Mental Disorders (4th edn) (DSM-IV). Washington, DC: APA.

Bair, M. J., Robinson, R. L., Eckert, G. J., et al (2004) Impact of pain on depression treatment response in primary care. Psychosomatic Medicine, 66, 17-22.

Blier, P. \& Abbott, F. V. (200I) Putative mechanisms of action of antidepressant drugs in affective and anxiety disorders and pain. Journal of Psychiatry and Neuroscience, 26, 37-43.

Feinmann, C. \& Newton-John, T. (2004) Psychiatric and related management considerations associated with nerve damage and neuropathic trigeminal pain. Journal of Orofacial Pain, 18, 360-365.

Fishbain, D. A. (1999) The association of chronic pain and suicide. Seminars in Clinical Neuropsychiatry, $\mathbf{4}$, 221-227.

Gilmer, W. \& McKinney, W. T. (2003) Early experience and depressive disorders: human and non-human primate studies. Journal of Affective Disorders, 75, 97-II3.

Greenberg, P. E., Leong, S. A., Birnbaum, H. G., et al (2003) The economic burden of depression with painful symptoms. Journal of Clinical Psychiatry, 64, 17-23.

Katona, C., Peveler, R., Dowrick, C., et al (2005) Pain symptoms in depression: definition and clinical significance. Clinical Medicine, 5, 390-395.

Royal College of Physicians \& Royal College of Psychiatrists (2003) The Psychological Care of Medical Patients. A Practical Guide. London: Royal College of Physicians/Royal College of Psychiatrists. http:// www.rcpsych.ac.uk/publications/cr/council/crl08.pdf

Von Knorring, L. \& Ekselius, L. (1994) Idiopathic pain and depression. Quality of Life Research, 3, S57-S68.

Von Knorring, L., Perris, C., Oreland, L., et al (1984) Pain as a symptom in depressive disorders and its relationship to platelet monoamine oxidase activity. Journal of Neural Transmission, 60, 1-9.

World Health Organization (1992) The ICD-IO Classification of Mental and Behavioural Disorders: Clinical Descriptions and Diagnostic Guidelines. Geneva: WHO. 